\title{
MASTOCITOMA CUTÂNEO EQUINO: QUANDO SUSPEITAR?
}

(Equine cutaneous mast cell tumor: when suspect?)

Jéssica Rodrigues Silva-Meirelles, Eduarda Maciel Busato, Renato Silva Sousa, Ivan

Deconto, Juliana Sperotto Brum, Peterson Triches Dornbusch ${ }^{1}$

\begin{abstract}
${ }^{1}$ Correspondência: petriches@gmail.com
RESUMO: O mastocitoma é uma lesão nodular pouco observada na espécie equina, porém pode apresentar características que se destacam na suspeita de uma lesão tumoriforme e difere clínica e patologicamente dos mastocitomas comumente observados em outras espécies. Por isso, objetivou-se relatar um caso clínico de mastocitoma cutâneo em um potro e salientar as principais diferenças observadas tanto com as outras principais lesões cutâneas equinas, como com os mastocitomas de outras espécies. Um potro de dois anos apresentava uma massa no tecido subcutâneo do pescoço que foi retirada cirurgicamente, e após exame histopatológico diagnosticou-se mastocitoma. Macroscopicamente a massa media $2,8 \times 2,0 \times 1,5 \mathrm{~cm}$, era firme ao corte, com superfície caseosa entremeada por tecido brancacento. Microscopicamente apresentava focos de proliferação de células redondas, com citoplasma repleto por finos grânulos basofílicos, em meio a extensas áreas de necrose com mineralização central. O exame citológico não foi conclusivo como na maioria dos tumores de mastócitos, pois acredita-se que foi puncionada uma área de necrose, comum nos mastocitomas de cavalos. Diferentemente do observado em cães, espécie em que é comum, em cavalos o tumor é benigno. É constituído de uma única massa solitária, diferentemente do sarcoide equino e raramente observa-se alteração na pele, como observado no tecido de granulação e no carcinoma de células escamosas. A excisão cirúrgica é curativa.
\end{abstract}

Palavras-chave: dermatopatologia veterinária; doenças de equinos; lesões nodulares

ABSTRACT: The mast cell tumor is a nodular lesion rarely observed in equine species, but may have features that stand out in a suspicion nodular injury and differs clinically and pathologically of mast cell tumors commonly observed in other species. Therefore, the objective was to report a case of cutaneous mast cell tumor in a foal and highlight the main differences observed with the most of other equine cutaneous lesions as with mast cell tumors of other species. A two-year foal presented a mass in the subcutaneous tissue of the neck that was surgically removed, and diagnosed mastocytoma trought a histopathological examination. Macroscopically the measure mass was $2.8 \times 2.0 \times 1.5 \mathrm{~cm}$, firm at cut, with caseous surface interspersed with whitish tissue. Microscopically, it presented focused proliferation of round cells with cytoplasm full of fine basophilic granules, amid extensive areas of necrosis with central mineralization. The cytological examination was not conclusive as in most mast cell tumors, and it is believed that was punctured a necrotic area, common in mast cell tumors in horses. Different from that observed in dogs, a species in which the tumor is common, in horses the tumor is benign. It consists of a single solitary mass, unlike the equine sarcoid and changes in the skin are rarely observed, as they are in the granulation tissue and squamous cell carcinoma. Surgical excision is curative.

Key Words: diseases of horses; nodular lesions; veterinary dermatopathology 
INTRODUÇÃO

Lesões cutâneas em cavalos, principalmente tumorais, estão entre os principais problemas encontrados na clínica equina (Marcolongo-Pereira, 2014). Em um estudo realizado na Região Central do Rio Grande do Sul, dentre as alterações cutâneas, as alterações tumoriformes da pele, neoplásicas ou não, mostraram uma prevalência de $77,6 \%$ (Souza et al., 2011). Já em outro estudo de causas de mortes em equinos (MarcolongoPereira, 2014), realizado na Região Sul do Rio Grande do Sul, somente as lesões tumoriformes cutâneas, também neoplásicas ou não, perfizeram um total de $84,6 \%$. Há um estudo retrospectivo recente que descreve 964 tumores equinos, ressaltando a importância desses para a espécie (Knowles et al., 2015). Apesar de pouco prevalente, os dois últimos estudos citados descrevem casos de mastocitoma cutâneo: $2 \%$, incluindo tumores de todos os sistemas (Marcolongo-Pereira, 2014) e 4\%, somente tumores cutâneos (Knowles et al., 2015).

Apesar de bem descrito em todas as espécies domésticas, a incidência do mastocitoma cutâneo em equinos, assim como em bovinos e suínos, é baixa (Goldschmidt e Hendrick, 2002; Millward et al., 2010). Alguns autores (Souza et al., 2011) não encontraram nenhum resultado positivo para mastocitoma ao avaliar 108 amostras de pele de cavalos na Região Central do Rio Grande do Sul apresentando tumorações. Nos equinos, os mastocitomas são invariavelmente benignos $e$ tendem a regredir espontaneamente, fazendo com que alguns autores questionem o caráter neoplásico desta afecção e tenham o diagnóstico como algo dificultoso (Goldschmidt e Hendrick, 2002). Apesar destes fatos contrários ao comumente observado, na literatura podemos observar alguns dados que nos levam a crer que 0 mastocitoma equino apresenta algumas descrições que merecem destaque na diferenciação das outras principais lesões tumoriformes da espécie.

Sarcoide equino, tecido de granulação e carcinoma de células escamosas são as principais alterações tumorais observadas na pele dos equinos (Valentine, 2006; Souza et al., 2011; Marcolongo-Pereira, 2014). O mastocitoma apresenta alguns aspectos que merecem consideração mediante uma suspeita de lesão tumoral equina e pode ser colocado na lista de diagnóstico diferencial juntamente com essas outras lesões. Outro ponto são algumas características histopatológicas do mastocitoma equino que difere da maioria dos mastocitomas comumente observados.

Levando em conta todas essas considerações, o objetivo deste trabalho é relatar os aspectos clínicos e patológicos de um caso de mastocitoma equino, enfatizando as principais características que 0 diferencia de outras lesões tumoriformes cutâneas em equinos para que uma suspeita clínica seja bem embasada, descrever os principais pontos diferenciais com as outras espécies e citar os principais métodos de diagnóstico.

\section{MATERIAL E MÉTODOS}

Um potro de dois anos, SRD, 290 quilos, não castrado, foi encaminhado ao Setor de Grandes Animais do Hospital Veterinário da UFPR por apresentar uma massa no pescoço, próximo à laringe. Dados clínicos e de manejo foram coletados com 0 proprietário e realizou-se exame clínico geral, específico da pele e região cervical.

Citologia aspirativa por agulha fina foi realizada com a utilização de uma agulha $25 \times 7$ introduzida na massa 
tumoral segurada manualmente. A agulha estava conectada à uma seringa de $5 \mathrm{~mL}$. Foi aplicada sucção, redirecionada a agulha três vezes, relaxada a sucção e então retirada a agulha da massa. Para realização do esfregaço, foi necessário comprimir a amostra entre duas lâminas de vidro devidamente limpas que simultaneamente foram deslocadas em sentido contrário. As amostras foram encaminhadas ao Laboratório de Patologia Veterinária (LPV) da UFPR. As preparações citológicas foram coradas com corante de Wright (coloração tipo Romanowsky).

Para realização do procedimento cirúrgico o animal foi deixado em jejum. Foi realizada medicação pré-anestésica com acepromazina $(0,05 \mathrm{mg} / \mathrm{kg})$ e xilazina $(0,5 \mathrm{mg} / \mathrm{kg})$. A indução foi realizada com cetamina $(2,2 \mathrm{mg} / \mathrm{kg})$ e midazolam $(0,1 \mathrm{mg} / \mathrm{kg})$. A manutenção anestésica foi realizada com isoflurano. Foi realizado bloqueio local da região do nódulo com cloridrato de lidocaína $(7,0$ $\mathrm{mg} / \mathrm{kg}$ ) e procedeu-se a retirada da massa, medindo aproximadamente 3,0 $\mathrm{cm}$ de diâmetro, com auxílio de eletrocautério. A ferida cirúrgica foi suturada com fio não absorvível sintético em padrão simples contínuo. 0 local foi higienizado com solução tópica de iodopovidona a $10 \%$ e tratado com pomada a base de alantoína e óxido de zinco.

O fragmento de pele obtido foi imediatamente fixado em formol a $10 \%$ tamponado e encaminhado ao LPV da UFPR. Após fixação, foi processado rotineiramente para histopatologia e corado pela hematoxilina e eosina. $O$ equino foi acompanhado durante sete dias, quando foi realizada a retirada dos pontos.

\section{RESULTADOS E DISCUSSÃO}

A avaliação da massa subcutânea retirada do pescoço deste equino revelou um processo proliferativo de origem em mastócitos e, baseado na histopatologia, o diagnóstico foi de mastocitoma. Durante o acompanhamento clínico o equino não apresentou alterações.

Mastocitomas em equinos são descritos mais comumente em machos e com uma variação de idade de 1-25 anos e média de 9 anos (Goldschmidt e Hendrick, 2002; Scott e Miller Jr., 2011), o que está de acordo com as características do potro deste relato. Ao exame clínico, na região cervical cranial, próximo à laringe, no lado esquerdo, observou-se uma massa circular de apoximadamente três centímetros, localizada no tecido subcutâneo, não sensível à palpação. Todos os outros parâmetros encontravam-se conforme 0 esperado para a espécie equina. Em dois casos de mastocitoma equino (Brown et al., 2007; Goldschmidt e Hendrick, 2002) os animais também não apresentavam outras anormalidades além da lesão cutânea. Segundo o proprietário, o nódulo havia sido observado há 12 semanas e, desde então, apresentou crescimento progressivo. O desenvolvimento do tumor neste caso foi lento, o que está de acordo com o descrito na literatura (Scott e Miller Jr., 2011). Na descrição de outro caso (Brown et al., 2007), o crescimento ocorreu em três semanas atingindo $2,0 \mathrm{~cm}$.

No exame citológico, observou-se grande quantidade de macrófagos em meio a um menor número de neutrófilos e debris celulares. Observaram-se raros grupos coesos de células fusiformes com leve a moderada atipia. O fundo da amostra era composto por grande quantidade de material amorfo azul escurecido. A amostra demonstrou 0 desenvolvimento de um processo inflamatório de curso crônico e predomínio de macrófagos. O diagnóstico citológico foi sugestivo de inflamação, porém não excluiu a existência de um processo neoplásico 
associado, sendo recomendada a exérese nodular. A literatura (Brown et al., 2007) cita que na citologia aspirativa por agulha fina realizada em um mastocitoma equino observam-se células redondas, de aparência uniforme com núcleos ovais ou circulares e cromatina agregada. Junto a isso, há ocasionais eosinófilos e numerosos mastócitos, tendo diagnóstico sugestivo de mastocitoma. Para muitas espécies o aspirado citológico por agulha fina pode apresentar um diagnóstico presuntivo de mastocitoma (Scott e Miller Jr., 2011) (Fig. 2A). Acredita-se que em nosso caso, a área aspirada não tenha sido representativa de uma porção com células neoplásicas.

A pele sobre a região lesada não apresentava qualquer alteração. À palpação, o nódulo era móvel, bem delimitado e de consistência firme. Segundo alguns autores (Samii et al., 1997) os mastocitomas em equinos emergem como massas focais, variando normalmente entre $0,2-20,0 \mathrm{~cm}$ de diâmetro, podendo acometer derme e/ou subcutâneo. São firmes ou flutuantes, por vezes encapsulados (Scott e Miller Jr., 2011). Nos membros, quando ocorrem, encontram-se nas proximidades articulares e podem apresentar pontos de calcificações (Samii et al., 1997). Macroscopicamente o nódulo representava essa descrição: media 2,8 x 2,0 x 1,5 cm; ao corte era firme; a superfície de corte era constituída predominantemente por focos de massa amarelada de aspecto caseoso, com áreas firmes (interpretado como tecido mineralizado), entremeada por tecido macio brancacento (Fig. 1).

Microscopicamente, observam-se múltiplos focos de proliferação celular, não delimitada, não encapsulada, organizada em curtos cordões celulares e entremeada por grande quantidade de estroma fibrovascular. As células são arredondadas, apresentando moderada anisocitose e anisocariose. citoplasma destas células é pouco delimitado, repleto por finos grânulos levemente basofílicos. O núcleo variava de arredondado a oval com 1-3 nucléolos bem evidentes. Agregados de células neoplásicas foram observados no interior de vasos sanguíneos. Em meio a proliferação havia infiltrado eosinofílico difuso acentuado. Múltiplas áreas focalmente extensas de necrose também podiam ser observadas, com áreas de mineralização central (Fig. 1).

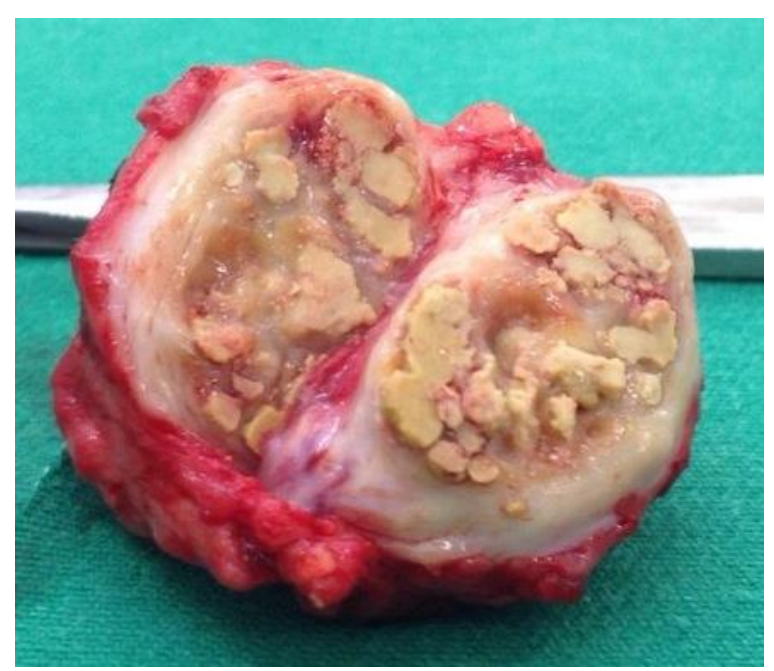

Figura 1 - Mastocitoma cutâneo equino. Nódulo caracterizado por focos de massa amarelada de aspecto caseoso, com áreas firmes (interpretado como tecido mineralizado), entremeada por tecido macio brancacento.

A descrição histopatológica está de acordo com a descrita por outros autores. Além das alterações características do mastocitoma bem diferenciado (mastócitos com núcleo ovoide e eosinófilos) (Fig. 2C), alguns autores (Brown et al., 2007) observaram também necrose multifocal, macrófagos espalhados contendo pigmento marromdourado compatível com hemossiderina, inflamação granulomatosa, colagenólise e fibrose extensa. Acreditamos que tenha sido uma dessas áreas extensas de necrose que tenha sido puncionada durante 0 exame citológico, não permitindo assim que o tumor tenha sido suspeitado mediante a citologia. Apesar 
da observação de células neoplásicas no interior de vasos sanguíneos, não foram descritos outros critérios de malignidade. As áreas de mineralização distrófica como as observadas podem ser bem abrangentes no nódulo e a alteração pode ser erroneamente diagnosticada como calcinose circunscrita. Nesses casos, os cordões de mastócitos neoplásicos restringemse a pequenos aglomerados residuais entre as grandes áreas de necrose (Scott e Miller Jr., 2011). Como a maioria dos mastocitomas equinos apresentam mastócitos bem diferenciados, a análise histopatológica é suficiente para o diagnóstico, porém um simples critério adicional de comprovação seria a técnica de histoquímica do Azul de Toluidina, onde a metacromasia dos grânulos citoplasmáticos das células é evidenciada (Fig. 2D) (Goldschmidt e Hendrick, 2002).

Dentre as lesões tumoriformes cutâneas equinas comuns - sarcoide equino, tecido de granulação e carcinoma de células escamosas - o mastocitoma apresenta algumas características semelhantes e isso, muitas vezes, o faz uma suspeita clínica consistente. Características como apresentação macroscópica e localização são os principais pontos que devem ser levados em consideração na hora de incluir o mastocitoma equino na lista de diagnóstico diferenciais.

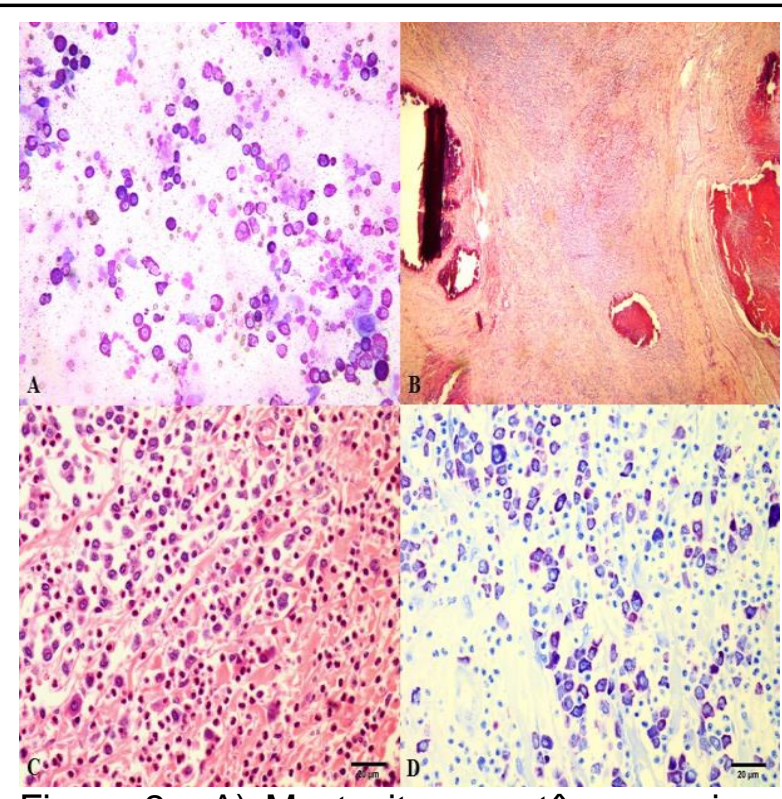

Figura 2 - A) Mastocitoma cutâneo canino. Exemplo de exame citológico evidenciando mastócitos bem diferenciados e granulação citoplasmática, comumente observado em aspirados citológicos de outras espécies. Wright, obj. 40x. B) Mastocitoma cutâneo equino. Observam-se grandes e extensas áreas de necrose com centro mineralizado entremeado de proliferação de mastócitos neoplásicos bem diferenciados. HE, obj. 4x. C) Mastocitoma cutâneo canino. Exemplo de neoplasma bem diferenciado evidenciando células redondas com núcleos ovoides e grande quantidade de eosinófilos. HE, obj. 40x. D) Mastocitoma cutâneo canino. Exemplo da técnica de histoquímica do Azul de Toluidina evidenciando grânulos metacromáticos intracitoplasmáticos. Obj.40x.

A literatura cita que o mastocitoma cutâneo equino apresenta predileção pela cabeça e membros (Goldschmidt e Hendrick, 2002). O mesmo pode ser observado com o sarcoide equino, que apresenta predileção por ambos os sítios, incluindo ainda a região abdominal ventral (Souza et al., 2011); e com o tecido de granulação que tem como predileção os membros por serem áreas fáceis de lesão (Lloyd et al., 2003). O carcinoma de células escamosas difere dos anteriores sendo o principal neoplasma observado na terceira pálpebra de equinos (Valentine, 2006), no entando, há relato de um 
mastocitoma nesta localização

(Goldschmidt e Hendrick, 2002).

A característica de uma única massa é comum no mastocitoma equino (Scott e Miller Jr., 2011). A literatura cita a descrição de massas múltiplas, porém em uma localização quase restrita do corpo (Millward et al., 2010). O mesmo não ocorre no sarcoide equino, onde a ocorrência de múltiplas massas é extremamente comum, sendo este um ponto importante na diferenciação clínica. Em um trabalho realizado na Região Central do Rio Grande do Sul a prevalência de sarcoides únicos foi de $27,5 \%$ (Souza et al., 2011). As outras lesões tumoriformes comuns em equinos geralmente apresentam-se como massas únicas (Lloyd et al., 2003; Scott e Miller Jr., 2011).

É comum a pele estar íntegra, porém raramente pode apresentar alopecia, hiperpigmentação ou ulceração (Seeliger et al., 2007; Scott e Miller Jr., 2011). No carcinoma de células escamosas e no tecido de granulação pode haver ulceração e/ou exuberância de tecido neoformado (Lloyd et al., 2003; Scott e Miller Jr., 2011). No sarcoide equino, a característica macroscópica depende da categoria clínica: verrucoso, fibroblástico, misto ou oculto (Souza et al., 2011). Levando em consideração essa classificação, o sarcoide oculto não será diferente clinicamente da maioria dos mastocitomas.

$\mathrm{O}$ fato dos mastocitomas equinos regredirem espontaneamente é um ponto que merece destaque. Geralmente essa alteração é mais observada em potros (Goldschmidt e Hendrick, 2002; Scott e Miller Jr., 2011). Outro neoplasma equino que apresenta regressão em sua forma cutânea é o linfoma. Linfomas subcutâneos em éguas tendem a regredir quando estas estão prenhes ou quando há a remoção de tumores ovarianos, pois são modulados por influências hormonais
(Scott e Miller Jr., 2011). Ainda em equinos jovens, o mastocitoma também pode se caracterizar por múltiplas lesões distribuídas pelo corpo. Este padrão é semelhante à mastocitose cutânea maculopapular (urticária pigmentosa) relatada em humanos (Scott e Miller Jr., 2011). Tanto a capacidade de regressão quanto a forma de mastocitose cutânea são bem descritos nos mastocitomas na espécie felina (Scott et al., 2001).

Há descrições de mastocitomas malignos na espécie equina (Scott e Miller Jr., 2011), mas o fato de haver regressão tumoral o classifica como um comportamento benigno na maioria das vezes. Comportamento que também é descrito para gatos, espécie em que a neoplasia é pouco comum (Goldschmidt e Hendrick, 2002). Diferentemente em cães, o mastocitoma é o tumor cutâneo mais prevalente, sempre potencialmente maligno e macroscopicamente exibe formas diversas. $\mathrm{Em}$ um estudo retrospectivo de 761 tumores cutâneos em cães, 158 eram mastocitomas (Scott et al., 2001). Em bovinos as descrições são raras e os neoplasmas também são malignos, com alto potencial metastático (Goldschmidt e Hendrick, 2002), assim como em suínos (Newman e Rohrbach, 2012).

O tratamento recomendado para cavalos é a excisão cirúrgica (Scott e Miller Jr., 2011), conforme realizado neste equino. Diferentemente do que tem sido observado em cães com neoplasmas agressivos, onde a remoção cirúrgica tem que ser acompanhada de terapia adjuvante com quimio/radioterápicos, nos equinos tende a ser curativa (Goldschmidt e Hendrick, 2002). Quando a cirurgia não é uma opção pode-se tentar fazer uso também de radioterápicos, criocirurgia ou de injeções de corticoides na base da lesão (Goldschmidt e Hendrick, 2002; Scott e Miller Jr., 2011). 


\section{CONCLUSÃO}

Mastocitoma cutâneo equino é um tumor pouco frequente. Diferentemente do observado em cães, espécie em que é comum, em cavalos o tumor é benigno. É constituído de uma única massa solitária, diferentemente do sarcoide e raramente observa-se alteração na pele, como observado no tecido de granulação e no carcinoma de células escamosas. Histologicamente, além das alterações comuns a todos os mastocitomas, extensas áreas de necrose com mineralização são bem observadas. $O$ exame citológico não foi conclusivo neste caso e acredita-se que em mastocitomas equinos, devido à alta prevalência de grandes áreas de necrose nesses tumores, este exame deve ser realizado com cautela. $O$ resultado negativo ou de inflamação, não exclui o mastocitoma.

\section{NOTAS INFORMATIVAS}

Reservado ao parecer CEUA.

\section{REFERÊNCIAS}

BROWN, H.M.; CUTTINO, E. e LEROY, B. A subcutaneous mass on the neck of a horse. Veterinary Clinical Pathology., v36, p.109-113, 2007.

GOLDSCHMIDT, M.H. e HENDRICK, M.J. Tumors of the skin and soft tissues. In: MEUTEN, D.J. (Ed.) Tumors in Domestic Animals. $4^{\text {th }}$ ed: lowa State Press, 2002. p. 45-118.

KNOWLES, E.J.; TREMAINE, W.H.; PEARSON, G.R. et al.. A database survey of equine tumours in the United Kingdom (Resumo). Equine Veterinary Journal, 2015.

MILLWARD, L.M.; HAMBERG, A.; MATHEWS, J. et al. Multicentric mast cell tumors in a horse (Resumo). Veterinary Clinical Pathology, v39, p.365-70, 2010.
MARCOLONGO-PEREIRA, C.; ESTIMA-SILVA, P.; SOARES, M.P. et al. Doenças de equinos na região Sul do Rio Grande do Sul. Pesquisa Veterinária Brasileira, v34, p.205-210, 2014.

NEWMAN, S.J. e ROHRBACH, B. Potbellied pig neoplasia: $A$ retrospective case series (2004-2011). Journal of Veterinry Diagnostic Investigation, v24, p.1008-1013, 2012.

LLOYD, D.H.; LITTLEWOOD, J.D.; CRAIG, J.M. et al. Practical Equine Dermatology: Blackwell Science Ltda, lowa, 2003. p.63-99.

SAMII, V.F.; O'BRIENT, T.R. e STANNARD, A.A. Radiographic features of mastocytosis in the equine limb. Equine Veterinary Journal, v29, p.6366, 1997.

SCOTT, D.W. e MILLER JR., W.H. Equine Dermatology. St. Louis, MO: Elsevier Science. 2011. p.496-499.

SCOTT, D.W.; MILLER JR., W.H. e GRIFFIN, C.E. Muller e Kirk's small animal dermatology. $6^{\text {th }}$ Philadelphia: Saunders Company. 2001. p.1320-1330. SOUZA, T.M.; BRUM, J.S.; FIGHERA, R.A. et al. Prevalência dos tumores cutâneos de equinos diagnosticados no Laboratório de Patologia Veterinária da Universidade Federal de Santa Maria, Rio Grande do Sul. Pesquisa Veterinária Brasileira, v31, p.379-382, 2011.

VALENTINE, B.A. Survey of equine cutaneous neoplasia in the Pacific Northwest. Journal of Veterinary Diagnostic Investigation, v18, p.123126, 2006. 